\title{
Photoinduced Polyacrylate Based Polymer Electrolyte for Quasi-solid State Dye Sensitized Solar Cell Application
}

Tingting Xu, ${ }^{\dagger * *}$ Dechong Kong, ${ }^{\dagger 1}$ Zhenzhen Xi, ${ }^{1,2}$ Tao Huang, ${ }^{3}$ Xiulan Qin, ${ }^{1}$ Hongjing Wu, ${ }^{4 *}$ Kaichang Kou, ${ }^{1}$ Rumin Wang, ${ }^{1}$ Lixin Chen ${ }^{1}$ and Tingli $\mathrm{Ma}^{5}$

A novel polymer electrolyte poly(NAG) prepared from commercially available transparent photocurable nail art glue NAG is successfully developed for quasi-solid state dye sensitized solar cells (QS-DSSCs) application. The functional component in this poly(NAG) is revealed to be acrylate based group from the Fourier transform infrared spectroscopy (FTIR) measurement. Water contact angles tests showthe poly(NAG) films displayed contact angle less than $20^{\circ}$ when dripping liquid electrolyte containing iodide/tri-iodide redox couple. Meanwhile, electrochemical properties of poly(NAG) polymer based electrolyte are thoroughly investigated by cyclic voltammetry (CV) and electrochemical impedance spectroscopy (EIS). The poly(NAG) polymer electrolyte presents an a highest ionic conductivity of $0.51 \mathrm{mS} \cdot \mathrm{cm}^{-1}$ at room-temperature. Solar cell based on the poly(NAG) electrolyte reaches power conversion efficiency (PCE) of $1.46 \%$. This work demonstrates that this NAG is a novel, cheap, environmental friendly and efficient precursor for preparing polymer electrolyte for DSSCs application. Its abundance can significantly reduce cell fabrication cost, and this work opens a new way to look for promising resource for the application of DSSCs.

Keywords: Polymer electrolyte; Dye sensitized solar cell; Photoinduced polymerization; Ionic conductivity

Received 21 November 2018, Accepted 28 January 2019

DOI: $10.30919 / \mathrm{es} 8 \mathrm{~d} 698$

\section{Introduction}

With the huge energy demands, photovoltaic technology has been regarded as one of the most promising approaches to supply renewable and clean energy. The newly emerged energy conversion devices, such as polymer solar cells, dye sensitized solar cells, perovskite solar cells etc., have gained extensive research interests owing to their potential for cost-effective promise. $^{1-6}$ In particular, dye-sensitized solar cells (DSSCs) using the low cost materials and simple fabrication procedures, demonstrate themselves as excellent candidates for costeffective energy conversion applications. Generally, a DSSC is fabricated by attaching a photoanode of dye sensitized nanocrystalline $\mathrm{TiO}_{2}$ film on FTO glass with a platinum counter electrode, and a liquid electrolyte of iodide/tri-iodide redox couple was sandwiched in between. DSSCs has made a steadily development and a high power conversion efficiency (PCE) up to $14 \%$ has been realized by

Department of Applied Chemistry, School of Natural and Applied Sciences, Northwestern Polytechnical University, Xi'an, Shaanxi, 710129 China

${ }^{2}$ SPIC Xi'an Solar Power Co., Ltd, Xi'an, Shaanxi, 710000 China

'Department of Engineering Mechanics, School of Mechanics, Civil Engineering and Architecture, Northwestern Polytechnical University, Xi'an, Shaanxi, 710129, China

${ }^{4}$ Department of Applied Physics, School of Natural and Applied Sciences, Northwestern Polytechnical University, Xi'an, Shaanxi, 710129, China

Graduate School of Life Science and Systems Engineering, Kyushu Institute of Technology, 2-4 Hibikino, Wakamatsu, Kitakyushu, Fukuoka 808-0196 Japan

Tingting $X u \dagger$ and Dechong Kong $\dagger$ contribute equally.

*E-mail: tingtingxu@nwpu.edu.cn; wuhongjing@mail.nwpu.edu.cn cooperative sensitization of silyl-anchor and carboxyl-anchor dyes to the date. $^{7}$ However, DSSC using liquid iodide/tri-iodide electrolyte still faces stability problems to hinder its broad application, due to the leakage and volatility of the liquid electrolytes, photodegradation of the light harvesting dyes, and the electrode corrosion. Alternative approaches to replace liquid electrolyte are investigated, i. e. polymer electrolytes, ionic liquid electrolyte, solid-state ionic conductor etc. with comparable conductive properties. ${ }^{8-15}$ A variety of polymers such as poly(methyl methacrylate) (PMMA), poly(ethylene oxide) (PEO), poly(vinylidene fluoride-hexafluoropropylene) (PVDF-HFP), poly(vinyl chloride) (PVC), poly(acrylonitrile) (PAN) and so on, have been applied as polymer electrolytes in $\mathrm{DSSCs}^{16-20}$. Many the polymer electrolytes in DSSCs were synthesized by thermally or chemically initiated polymerization method, involving sophisticate polymerization conditions and time-consuming procedures.

Photo-induced polymerization is a feasible and efficient strategy to generate polymeric networks with low cost, high cure speed and little energy consumption. ${ }^{21,22}$ Previously, we reported a UV-curable borazinetype single source precursor for SiBNC ceramic materials. ${ }^{23}$ The precursors with multiple UV-curable groups (acrylate) can be converted rapidly with the existence of the photoinitiator under UV light. Herein, we prepared the photocurable polymer electrolyte for dye sensitized solar cell application. UV-curing to prepare polymer electrolyte matrix for DSSCs is indeed a good choice, not only simplifies the device fabrication procedures, but also reduces environment pollution. The UVinduced polymer electrolyte can trap the liquid electrolyte into its crosslinked polymer network and remain the dimensional stability at elevated temperature. Y. S. Kim et al. used a UV-cured polymer gel electrolyte formed by aliphatic urethane acrylate and photoinitiator for DSSC, retarding the back electron transfer from the $\mathrm{TiO}_{2}$ to the electrolyte. ${ }^{24} \mathrm{~S}$. R. Kim et al. studied a UV photo-crosslinkable electrolyte using 
poly(ethylene glycol) (PEG) combined with a bifunctional poly(ethylene glycol) diacrylate (PEGDA) for better stability of DSSCs. ${ }^{25}$ Photochemically produced quasi-linear copolymers based on monomer glycidyl methacrylate (GMA) in DSSCs were reported by M. Imperiyka et $a l^{26} \mathrm{~F}$. Bella et al. prepared a copolymer electrolyte in DSSCs by employing bisphenol A ethoxylate dimethacrylate (BEMA) and poly(ethylene glycol) methyl ether methacrylate (PEGMA), obtaining a PCE of 5.41\%. ${ }^{27}$ Later, they reached a higher PCE of $6.4 \%$ with cobaltbased redox couple and simultaneously kept the excellent long-term stability at a $1800 \mathrm{~h}$ aging test. ${ }^{28}$ Although the researches mentioned above achieved good performance in DSSCs, problems of high cost and toxicity of precursor materials are still waiting to be solved. For future commercial application of DSSCs, it is essentially important to develop innovative UV-curing materials with benefits of low cost and environment benignity.

In this paper, we adopted commercially available transparent photocurable glue named as NAG for nail art as the precursor to form polymer matrix. The main components of this glue consist of acrylic monomer and photoinitiator. It has the advantages of less toxic and simple production when applied as polymer electrolyte matrix in DSSCs. The polymerization process was investigated by Fourier transform infrared spectroscopy (FTIR), and the film morphology was characterized by scanning electron microscopy (SEM). The inhabitation capability of the poly(NAG) membrane was tested. Electrochemical properties and the photovoltaic performance of the DSSC fabricated by this new polymer matrix were studied. It successfully demonstrates that this commercial nail art glue NAG can be applied as a novel polymer electrolyte for quasi-solid state DSSCs. This new photocurable material could be extended to other kinds of energy conversion devices owe to its feasible preparation and low cost. ${ }^{29.32}$

\section{Experimental section}

\subsection{Materials}

1-butyl-3-methylimidazolium iodide (BMII, 99\%), guanidinium thiocyanate (GuSCN, 97\%), 4-tert-butylpyridine (tBP, 96\%), Iodine ( $\mathrm{I}_{2}$, 99.5\%), titanium diisopropoxide bis(acetylacetonate) (75 $\mathrm{wt} \%$ in isopropanol), acetonitrile ( $\mathrm{AN}, 99.5 \%$ ) and valeronitrile (VN, 99.5\%) were purchased from Sigma-Aldrich. Tetrabutylammonium iodide (TBAI, 99\%) was purchased from Macklin. Titanium tetrachloride $\left(\mathrm{TiCl}_{4}, 99 \%\right)$ was purchased from Aladdin. Fluorine doped tin oxide (FTO) glass (sheet resistance: 7 8 $\Omega \cdot \mathrm{cm}^{-2}$ ), chloroplatinic acid hexahydrate $\left(\mathrm{H}_{2} \mathrm{PtCl}_{6} \cdot 6 \mathrm{H}_{2} \mathrm{O}, 99.95 \%, \mathrm{Pt} \geq 37.5 \%\right)$, Ditetrabutylammonium cis-bis(isothiocy-anato)bis(2,2'-bipyridyl-4,4'dicarboxylato) ruthenium(II) (N719 dye) and $\mathrm{TiO}_{2}$ paste were purchased from Yingkou OPV new energy Co., Ltd.

\subsection{Preparation of polymer membrane and polymer electrolytes} Fluorine doped tin oxide substrates (FTO) was cleaned by successively sonication in bath of detergent water, deionized water, acetone and ethanol for 15 minutes, separately, and then air dried. The glue (NAG) was drop casted on the cleaned FTO glass, and then exposed on UV light radiation at certain illumination intensity. The as-obtained polymer was a free-standing membrane and can be peeled off easily. The polymer electrolyte was prepared by soaking the polymer film into a mixture of $\mathrm{I}^{\prime} / \mathrm{I}_{3}^{-}$electrolyte solution, i. e. the photo-polymerized polymer membrane poly(NAG) was immersed in a liquid electrolyte consisting of 0.1 $\mathrm{M} \mathrm{I}_{2}, 0.4 \mathrm{M}$ TBAI, 0.6 M BMII, 0.1 M GuSCN, and 0.5 M tBP in a mixture solvent of volatile $\mathrm{AN} / \mathrm{VN}(85: 15, \mathrm{v} / \mathrm{v})$ for $6 \mathrm{~h}$ followed our reported methods $\mathrm{s}^{16,33}$. The whole process to obtain the polymer gel electrolyte is illustrated as Scheme 1.

\subsection{Fabrication of quasi-solid state dye sensitized solar cells (QS- DSSCs)}

QS-DSSC was fabricated according to the procedure reported in the literature $^{34}$ and the device structure is shown as Scheme 1. A dilute bis(acetylacetonate) diisopropoxide titanium solution was spin coated onto the cleaned FTO substrate, the film was annealed at $500{ }^{\circ} \mathrm{C}$ for 30 min to form a compact $\mathrm{TiO}_{2}$ layer. $\mathrm{TiO}_{2}$ nanocrystalline layer was screen-printed on top of the $\mathrm{TiO}_{2}$ compact layer, and then gradually heated up to $500{ }^{\circ} \mathrm{C}$ for $15 \mathrm{~min}$. Finally, the $\mathrm{TiO}_{2}$ film was treated by $0.04 \mathrm{M} \mathrm{TiCl}_{4}$ aqueous solution at $70{ }^{\circ} \mathrm{C}$ for $30 \mathrm{~min}$, and then annealed at $500{ }^{\circ} \mathrm{C}$ for $30 \mathrm{~min}$. The $\mathrm{TiO}_{2}$ photoanode was then immersed into a 0.5

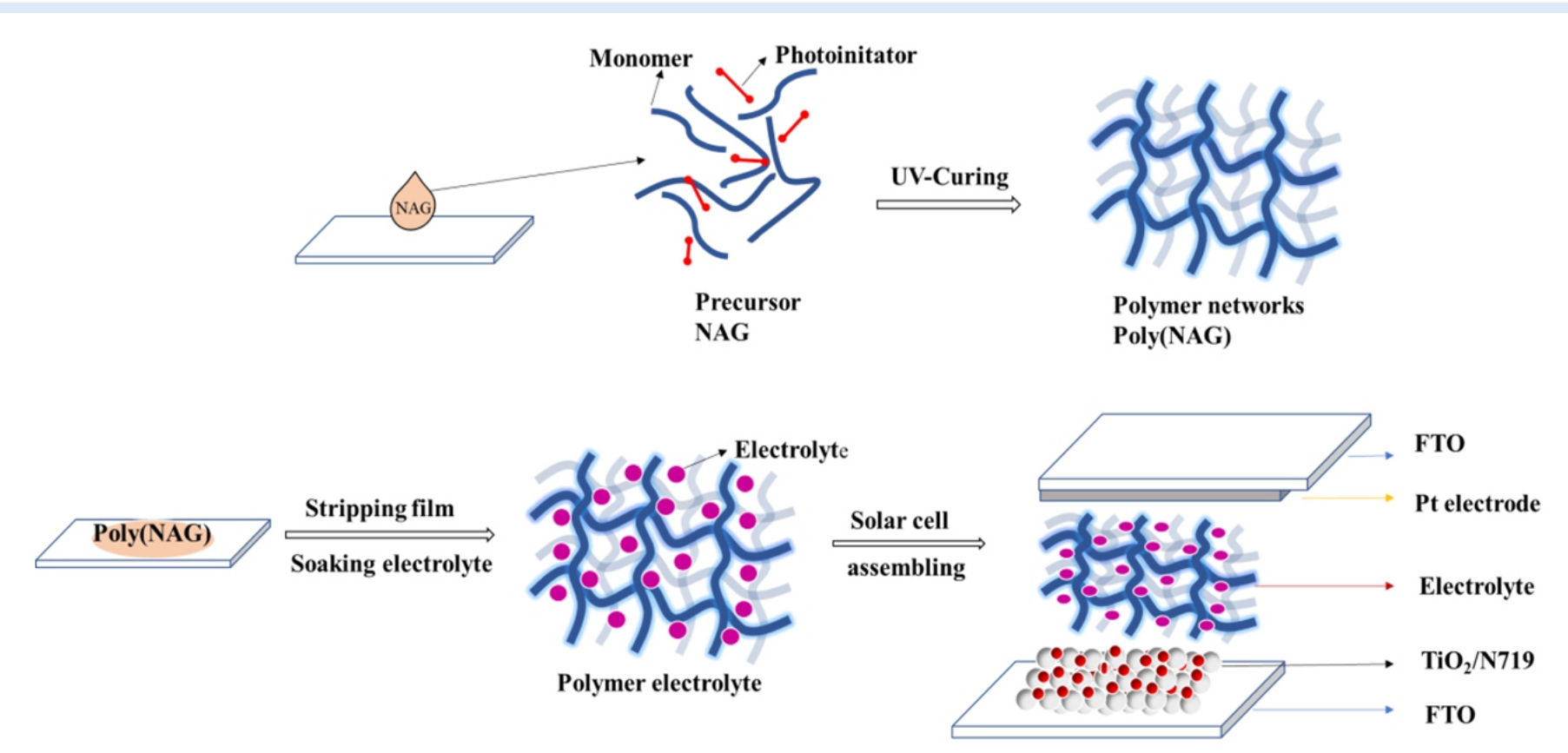

Scheme 1. Schematic illustration of preparation of photoinduced polymer electrolyte and the configuration of quasi-solid state dye sensitized solar cells. 
mM N719 dye solution for $24 \mathrm{~h}$ at ambient temperature, and then washed with ethanol to remove the unabsorbed dyes. Pt counter electrode was prepared by drop casting $5 \mathrm{wt} \% \mathrm{H}_{2} \mathrm{PtCl}_{6} \cdot 6 \mathrm{H}_{2} \mathrm{O}$ in isopropanol solution on the cleaned FTO glass, and then converted at $400{ }^{\circ} \mathrm{C}$ for $30 \mathrm{~min}$ to obtain a uniformly covered Pt film. The QSDSSCs were fabricated by sandwiched the polymer electrolyte between the dye sensitized $\mathrm{TiO}_{2}$ photoanode and the Pt counter electrode. The active area of a solar cell is typically $0.16 \mathrm{~cm}^{2}$.

\subsection{Characterization}

Surface morphology of the polymer membrane was examined by scanning electron microscopy (SEM, Su8010). The photo-polymerization process was monitored by Fourier transform infrared spectroscopy (FTIR, TENSOR) using thin $\mathrm{KBr}$ tablet as the sample holder. Surface wettability of the polymer film was performed by contact angle meter $\left(\mathrm{JC} 2000 \mathrm{C}, \mathrm{POWEREACH} \mathrm{R}^{\mathrm{R}}\right.$ ) at room temperature. Ionic conductivity of the polymer membrane was tested by electrochemical workstation (Princeton 4000) from $10000 \mathrm{~Hz}$ to $1 \mathrm{~Hz}$ at a potential interval of 10 $\mathrm{mV}$. The symmetrical cell was assembled by inserting the polymer electrolyte into two identical Pt electrodes. The ionic conductivity $(\sigma)$ of the polymer electrolyte can be obtained by the equation of $\sigma=\frac{L}{A \cdot R_{b}}$ where the resistance $\left(\mathrm{R}_{\mathrm{b}}\right)$ is obtained from the intercept of the Nyquist plot with the real axis, $\mathrm{A}$ is the area of electrode layer, and $\mathrm{L}$ is the thickness of the polymer electrolyte membrane. The electrochemical properties was examined by electrochemical workstation at the cyclic voltammetry mode (Princeton 4000) from -1 to $+1 \mathrm{~V}$ at a scan rate of 1 $\mathrm{mV} \cdot \mathrm{s}^{-1}$. The Tafel curve was measured from $-0.15 \mathrm{~V}$ to $+0.15 \mathrm{~V}$ at a scan rate of $0.1666 \mathrm{mV} \cdot \mathrm{s}^{-1}$ using the sandwiched symmetry cell. The current density-voltage (J-V) characteristic curve of the solar cell was tested by a Keithley 2401 instrument under a solar simulator (Nowdata SXDN-150E) under the light illumination intensity of $100 \mathrm{~mW} \cdot \mathrm{cm}^{-2}$, calibrated by a standard silicon solar cell.

\section{Result and discussion}

3.1 Effect of polymerization condition on the ionic conductivity of polymer electrolyte

In QS-DSSCs, the ionic conductivity of the polymer electrolyte is a key factor to determine the performance of solar cells. UV-curing conditions significantly influence the polymer network formation, affecting the polymer electrolyte properties especially the ionic conductivity. Herein, the variation trends of ionic conductivity $(\sigma)$ and bulk resistance $\left(\mathrm{R}_{\mathrm{b}}\right)$ of the poly(NAG) electrolyte prepared by different curing time and light illumination intensity were investigated as shown in Fig. 1. All of the polymer gel electrolytes were prepared by soaking in the liquid electrolyte for 6 hs. The ionic conductivity of the polymer electrolyte poly(NAG) was firstly tested under the UV light intensity of 100 $\mathrm{mA} \cdot \mathrm{cm}^{-2}$ at varied curing time. As shown in Fig. 1a, the curing time increases from $20 \mathrm{~s}$ to $120 \mathrm{~s}$, the ionic conductivity $(\sigma)$ of poly(NAG) gradually decreases from $0.267 \mathrm{~ms} \cdot \mathrm{cm}^{-1}$ to $0.068 \mathrm{~ms}^{\cdot} \mathrm{cm}^{-1}$, while the bulk resistance linearly increases as the curing time rises. The reason might be that a longer curing time would result in a higher crosslinked polymer network with smaller free-volume space. As reported by S. R. Kim et al. in their photopolymerized polymer electrolyte, the crosslinking degrees linearly increased with the light irradiation in the
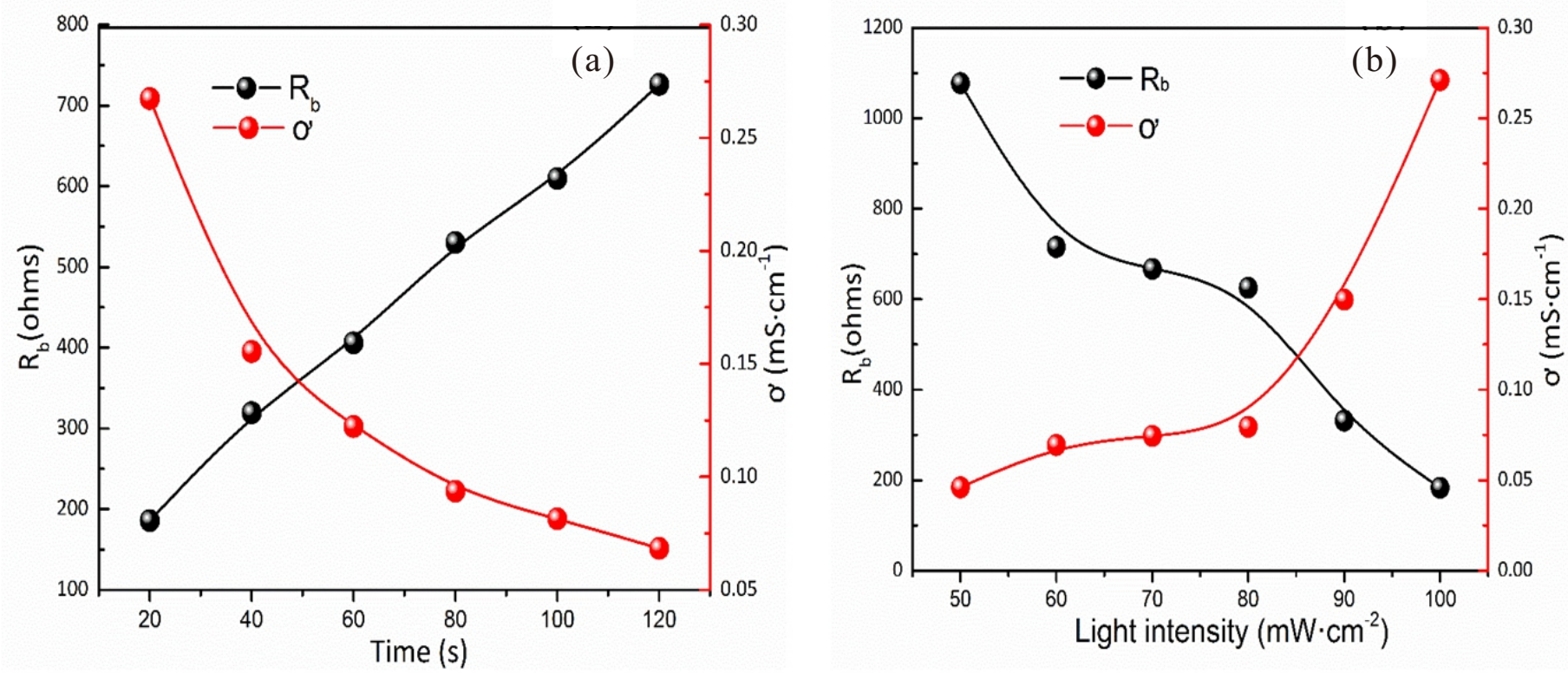

Fig. 1 Variation trends of ionic conductivity $(\sigma)$ and $R_{b}$ with illumination time (a) and illumination intensity (b) respectively.

Table 1 Summary of ionic conductivity of poly(NAG) polymer electrolyte prepared under different illumination time and illumination intensities.

\begin{tabular}{|c|c|c|c|c|c|c|}
\hline \multirow{2}{*}{$\begin{array}{l}\text { Polymer electrolyte } \\
\text { Curing time (s) }\end{array}$} & \multicolumn{6}{|c|}{ Ionic conductivity $\left(\mathrm{mS} \cdot \mathrm{cm}^{-1}\right)$} \\
\hline & 20 & 40 & 60 & 80 & 100 & 120 \\
\hline $100 \mathrm{~mW}^{2} / \mathrm{cm}$ & 0.267 & 0.155 & 0.122 & 0.093 & 0.081 & 0.068 \\
\hline Curing intensity $\left(\mathrm{mW} / \mathrm{cm}^{2}\right)$ & 50 & 60 & 70 & 80 & 90 & 100 \\
\hline$(20 \mathrm{~S})$ & 0.046 & 0.069 & 0.074 & 0.079 & 0.149 & 0.271 \\
\hline
\end{tabular}


time range of 10 mins to 60 mins. ${ }^{25}$ Therefore, mobile ions might not be able to move freely in the densely packed inter-penetrated polymer network. When elevating the light intensity at the constant curing time of $20 \mathrm{~s}$ shown in Fig. 1b, the ionic conductivity of poly(NAG) electrolyte was raised slowly from the light intensity of $50 \mathrm{~mA} \cdot \mathrm{cm}^{-2}$ to that of $80 \mathrm{~mA} \cdot \mathrm{cm}^{-2}$, and it had a rapid rise when the light intensity increased from $80 \mathrm{~mA} \cdot \mathrm{cm}^{-2}$ to $100 \mathrm{~mA} \cdot \mathrm{cm}^{-2}$, finally achieving a maximum $\sigma$ value of $0.270 \mathrm{~ms} \cdot \mathrm{cm}^{-1}$. The $R_{b}$ trends showed a reversed relationship of $\sigma$. Table 1 summarizes the ionic conductivity values changes under the light intensity and illumination time. The further increase of the ionic conductivity of the polymer gel electrolyte can be obtained by prolonging the soaking time in the liquid electrolyte, and the highest ionic conductivity of the poly(NAG) is $0.51 \mathrm{~ms} \cdot \mathrm{cm}^{-1}$ by immersing the membrane in the liquid electrolyte for $24 \mathrm{hrs}$.

\subsection{Structure analysis}

Fourier transform infrared spectroscopy (FTIR) is an important tool to identify functional groups or monitor group changes during the chemical reaction. Fig. 2 is the FT-IR spectrum of the precursor glue NAG before and after UV-irradiation. The crosslinking reaction in the NAG precursor was confirmed by observing the disappearance of the characteristic peaks at $1635 \mathrm{~cm}^{-1}$ and $815 \mathrm{~cm}^{-1}$ after the UV-irradiation, assigning to the stretching vibration at region of $1610-1640 \mathrm{~cm}^{-1}$ and the twisting vibration at $815 \mathrm{~cm}^{-1}$ for acrylic $\mathrm{C}=\mathrm{C}$ bonds. ${ }^{35}$ It indicates that the double bonds were thoroughly converted into the saturated bonds after the photo-polymerization of the NAG. The absorption peak at $1720 \mathrm{~cm}^{-1}$ generally arises from the $\mathrm{C}=\mathrm{O}$ bending in the carboxyl group. The new peaks at $902 \mathrm{~cm}^{-1}$ and $748 \mathrm{~cm}^{-1}$ were observed after the UVcuring. The peak of $748 \mathrm{~cm}^{-1}$ can be assigned to the characteristic peak of monosubstituted benzene, the peak at $902 \mathrm{~cm}^{-1}$ may represent $\mathrm{C}-\mathrm{H}$ surface bending vibration of substituted benzene, indicating that there might have aromatic compound in the NAG precursor either from the monomer or photoinitiator.

\subsection{Surface properties of the polymer membrane and the polymer electrolyte}

The surface morphology of the photo-induced polymer membrane poly(NAG) and corresponding polymer electrolyte were characterized by scanning electron microscope (SEM). As shown in Fig. 3a, poly(NAG) membrane shows a homogeneous wrinkled texture in the

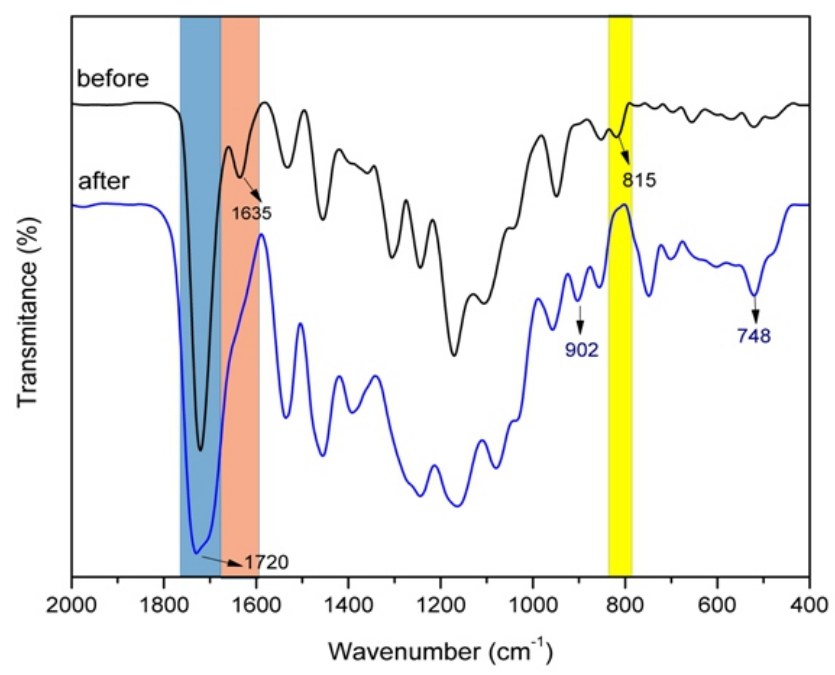

Fig. 2 FT-IR spectrum of the transparent photocurable glue NAG before (black line) and after (blue line) UV light irradiation. large magnification of $50 \mu \mathrm{m}$, proving that the NGA was successfully polymerized and uniformly covered the whole scan region without obvious pinholes. Nair et al. reported a similar wrinkled morphology for the photocurable polymer films, and they regarded that the wrinkled texture may due to the formation of the cross-linked domain of the polymer chain. ${ }^{36}$ Winkled texture typically relates to the thermal mechanical process of the film formation, i. e. relaxation of tension stress during solvent evaporation, as noticed before in our nanoridge $\mathrm{ZnO}$ films. ${ }^{37}$ High magnified SEM image of polymer poly(NAG) in Fig. $3 \mathrm{~b}$ shows an uneven surface and many bulges exist in the film. The SEM images of poly(NAG) electrolyte film (Fig. 3c\&3d) present a distinct morphology of individual islands compared with the pristine polymer film itself. It might due to some substances were corroded by the iodine ions. Overall, poly(NAG) electrolyte still presents a continuous film shape after the electrolyte dried up in Fig. 2d, demonstrating its robustness and corrosion resistance. The polymer has an intimate contact with the iodine/tri-iodine electrolyte, and the iodine ions would migrate through the polymer chain, thus the polymer film resistivity to the iodine redox couple is important. To the other hand, some polymers can dissolve in the iodide/tri-iodide electrolyte. Report found that nylon 6 is very easily soluble in 3-methoxypropionitrile solutions containing $\mathrm{I}_{3}^{-}$, due to the formation of the complex of $\mathrm{I}_{3}^{-}$-nylon 6 complex via the coordination of the $\mathrm{I}_{3}^{-}$to the hydrogen bonds of nylon 6 , thus the viscosity of the electrolyte is increasing for better device stability of DSSC than the liquid counterparts. ${ }^{38}$ Therefore, the polymer matrix absorbing the liquid electrolyte or partially dissolving in the liquid electrolyte might both improve the stability of QS-DSSCs.

\subsection{Liquid electrolyte imbibition}

Fig. 3 e\&3f shows photo images of the as-prepared polymer poly(NAG) membrane and its electrolyte film after absorbing $\mathrm{I}_{3}^{-} / \mathrm{I}^{-}$redox couple. Poly(NAG) itself is a transparent film and became light yellow after immersing in the $\mathrm{I}_{3}^{-} / \mathrm{I}^{-}$electrolyte. Contact angle measurements were performed on the poly(NAG) film surface to investigate its wettability behavior. Fig. $3 \mathrm{~g}$ shows that the poly(NAG) has a hydrophobic character with a contact angle of $82.5^{\circ}$ after dripping water droplet, thus its hydrophobicity may be able to avoid permeation of water residues. A remarkable decrease of the contact angle after dripping liquid electrolyte containing $\mathrm{I}_{3}^{-} / \mathrm{I}^{-}$redox couple was presented in Fig. $3 \mathrm{~h}$. The ploy(NAG) film appears complete wetting in a short time, leading to a contact angle less than $20^{\circ}$. It demonstrated that the poly(NAG) films have excellent wettability to absorb liquid electrolyte, thus it has the capacity to retain the liquid electrolyte in QS-DSSCs.

To further understand the mechanism of liquid electrolyte absorbency, the imbibition kinetics of poly(NAG) in $\mathrm{I}_{3}{ }^{-} / \mathrm{I}^{-}$liquid electrolytes were studied as shown in Fig. 4. The liquid absorbency can be obtained according to the Eq. 1 : $^{39}$

$$
\text { Liquid Absorbancy }=\frac{M_{2}-M_{1}}{M_{1}}
$$

where $M_{1}$ is the mass of the polymer film (g), and $M_{2}$ is the mass of the polymer absorbing the electrolyte $(\mathrm{g})$.

The ionic conductivity (left side) and liquid electrolyte loading capability (right side) are both presented as Y axis in Fig. 4 to well correlate the electrolyte loading equilibrium and ionic conductivity changes. The poly(NAG) reached its electrolyte loading equilibrium at a swelling time around $10 \mathrm{~h}$ (blue line), and no further absorbency increased under longer immersion time. The room-temperature ionic conductivity of poly(NAG) (black line) follows the same trends as the absorbency changes, i. e. it increased rapidly at the first few hours, and then gradually reached to its maximum value of $0.46 \mathrm{~ms} \cdot \mathrm{cm}^{-1}$ after 
retaining electrolyte for a period of $20 \mathrm{~h}$. A long testing time of both absorbency and ionic conductivity survey for poly(NAG) showed a relatively stable performance without distinct properties decay. The imbibition mechanism of polymer poly(NAG) was fitted by Fickian theory (Eq. 2): $:^{40}$

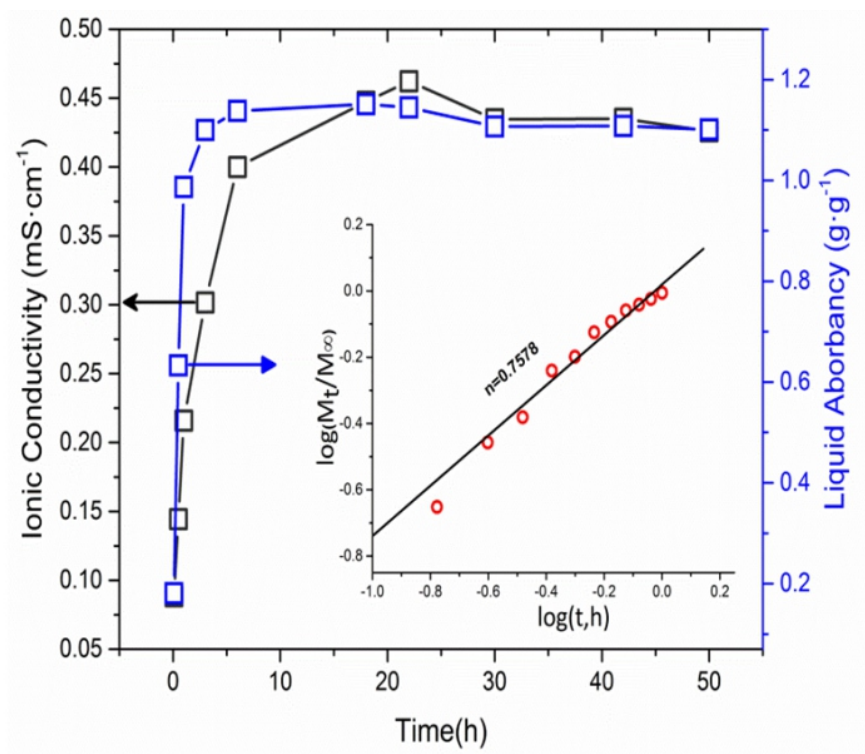

Fig. 4 Correlation between the ionic conductivity, liquid electrolyte loading and imbibition kinetics of the poly(NAG) polymer matrix in liquid electrolyte. The insets show the linear relationship between log $\left(\mathrm{Mt} / \mathrm{M}_{\infty}\right)$ and $\log (\mathrm{t})$.

$$
\frac{M_{\mathrm{t}}}{M_{\infty}}=k t^{n}
$$

where $M_{t}$ is the mass of the absorbed liquid electrolyte at time $t, M_{\infty}$ is the mass at equilibrium, $\mathrm{k}$ is a characteristic rate constant relevant to the properties of polymer matrix, and $\mathrm{n}$ is a transport number characterizing the transport mechanism. The $\mathrm{n}$ value can be calculated by fitting curve of $\log \left(\mathrm{Mt} / \mathrm{M}_{\infty}\right)$ vs $\log (\mathrm{t})$ as shown in the inserted figure of Fig. 4. A $\mathrm{n} \leq 0.5$ suggests a Fickian or Case I transport behavior, indicating that the poly(NAG) structural relaxation is much faster than its diffusion; When $\mathrm{n}$ is equal to 1 , giving a non-Fickian or Case II mode of transport, it suggests that the liquid electrolyte inhibition is controlled by the diffusion process. $0.5<\mathrm{n}<1$ refers to an anomalous or a Case III mode in which structural relaxation is comparable to diffusion. ${ }^{41}{ }^{42,43}$ For the poly(NAG) membrane, the $\mathrm{n}$ value is found to be 0.7578 in the insert figure of Fig. 4, presenting that the polymer structural relaxation is comparable to the diffusion rate. Thus the loading of liquid electrolyte is predominated by osmotic pressure.

\subsection{Temperature dependent ionic conductivity}

The ionic conductivity $(\sigma)$ and activation energy $\left(E_{a}\right)$ are crucial parameters determining the ion transport property of the polymer electrolyte, and they affect the final performance of DSSCs to a great extent. Fig. 5 shows the ionic conductivity-temperature plot of the polymer poly(NAG) electrolyte over the temperature range of $30{ }^{\circ} \mathrm{C}$ to $65^{\circ} \mathrm{C}$, well following an Arrhenius relationship of $\sigma=\sigma_{0} \exp \left(-E_{d} k T\right)$. The ionic conductivity at $65{ }^{\circ} \mathrm{C}$ are $1.91 \mathrm{mS} \cdot \mathrm{cm}^{-1}$ for poly(NAG) electrolyte and $0.51 \mathrm{mS} \cdot \mathrm{cm}^{-1}$ for pure liquid electrolyte of $\mathrm{I}_{3}^{-} / \mathrm{I}^{-}$redox couple. $\mathrm{E}_{\mathrm{a}}$ of the poly(NAG) is calculated to be $22.082 \mathrm{~kJ} / \mathrm{mol}$ according to above equation. $\mathrm{E}_{\mathrm{a}}$ is the value to identify the transport rate of the $\mathrm{I} / \mathrm{I}_{3}^{-}$in polymer electrolyte, and lower $\mathrm{E}_{\mathrm{a}}$ value implied faster ions movement.
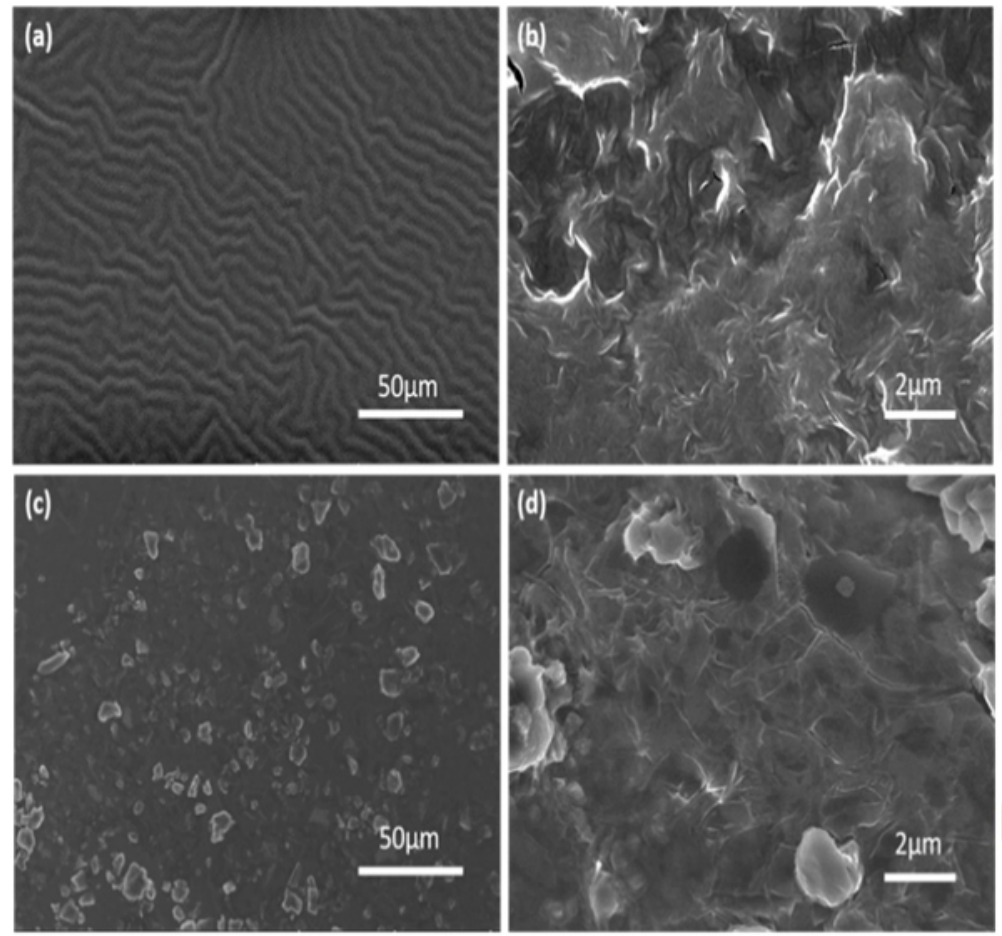

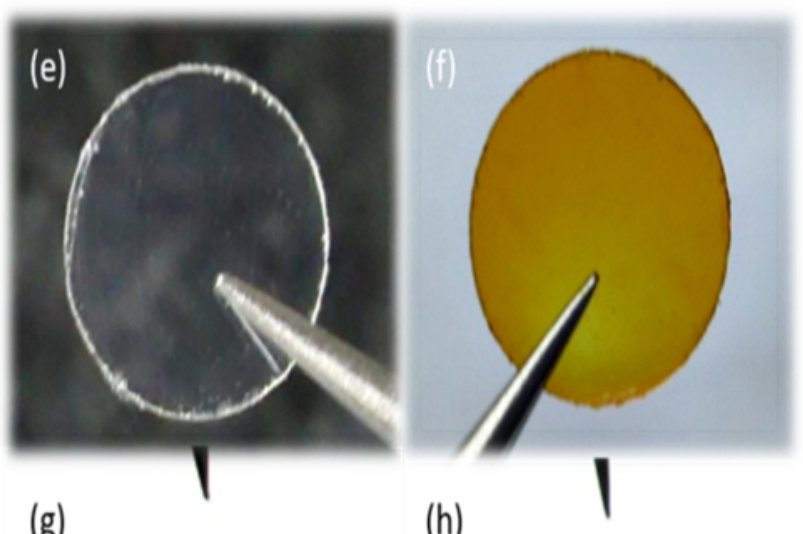

(g)

(h)

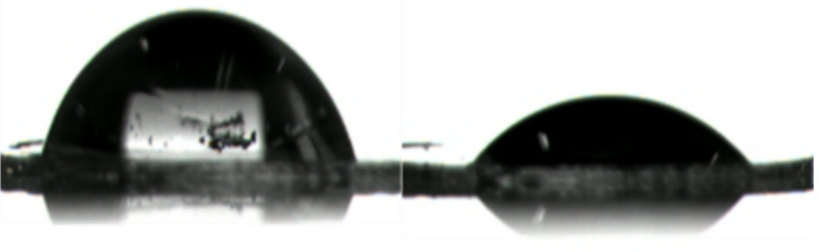

Water

\section{Liquid electrolyte}

Fig. 3 Top-view SEM images of photocurable polymer poly(NAG) (a, b) and poly(NAG) electrolyte (c, d). Pictures of free-standing poly(NAG) membrane (e) and poly(NAG) absorbing electrolyte (f). Water contact angle images of poly(NAG) film absorbing water (g) or liquid electrolyte of $\mathrm{I}_{3}^{-} / \mathrm{I}^{-}$ redox couple $(\mathrm{h})$. 


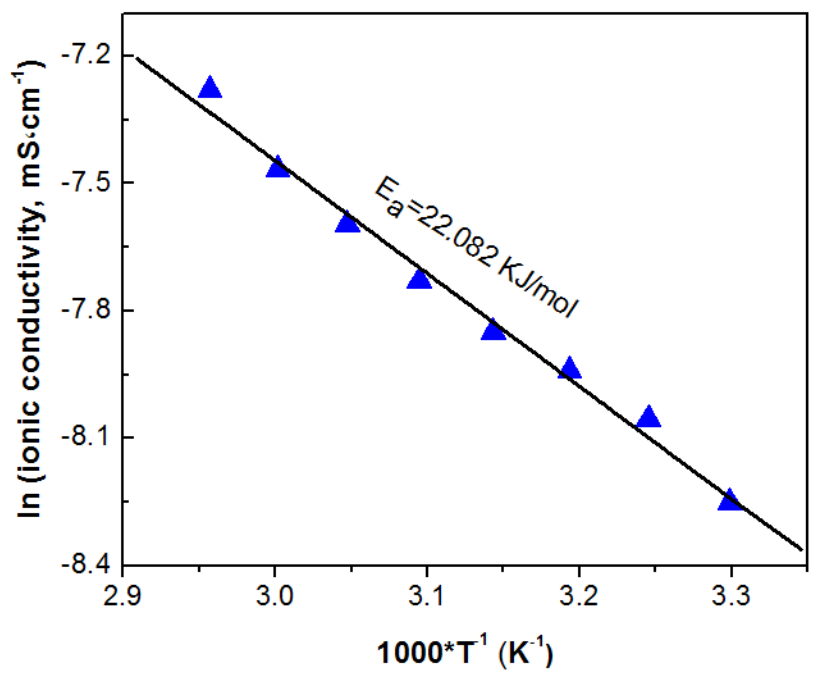

Fig. 5 Temperature dependent ionic conductivity of polymer electrolytes.

\subsection{Electrochemical performance}

Cyclic voltammetry (CV) provides information about the oxidation and reduction processes of the species in the electrolyte. Electrocatalytic behavior of the poly(NAG) were tested by temperature dependent $\mathrm{CV}$ curves at a series of temperature from $30^{\circ} \mathrm{C}$ to $65^{\circ} \mathrm{C}$ as shown in Fig. 6a. A couple of redox peaks in Fig. 6a can be ascribed to the electrocatalytic activity of polymer gel electrolyte to the triiodides, ${ }^{42}$ indicating that the $\mathrm{I} / \mathrm{I}_{3}^{-}$redox couples can migrate in the poly(NAG) networks. The migration of the $\mathrm{I}_{3} \mathrm{I}_{3}^{-}$redox couple in the polymer matrix may not be distinctly distinguished. The reactions represented by the redox peak are labeled inside the Fig. 6a. It can be also seen that the migration of redox ions and redox reaction kinetics are accelerated as the temperature increases from $30{ }^{\circ} \mathrm{C}$ to $65{ }^{\circ} \mathrm{C}$. The diffusion rate of $\mathrm{I}_{3}{ }^{-}$ in the electrolyte determines the Nernst diffusion impedance resistance of I and then directly affects the photovoltaic properties of DSSC. In the same scan potential, the larger diffusion-limited currents density $\left(\mathrm{J}_{\text {lim }}\right)$ reflects that the electrolysis of $\mathrm{I}_{3}^{-}$has a larger diffusion coefficient constant $\left(D_{\text {app }}\right)$, i. e. faster diffusion rate of $\mathrm{I}_{3}{ }^{-44} \mathrm{~J}_{\lim }$ is proportional to the $\mathrm{D}_{\text {app }}$ of $\mathrm{I}_{3}^{-}$, obeying the following eq. 3 :

$$
J_{\text {lim }}=\frac{2 n e_{0} D_{a p p} C_{I_{3}^{-}}-N_{A}}{l}
$$

where $\mathrm{n}$ is the electron number transferred in the reaction, $\mathrm{e}_{\mathrm{o}}$ is the elementary charge; $\mathrm{D}_{\text {app }}$ is the diffusion coefficient of triiodide; $C_{I_{3}}$ is the concentration of triiodide; $\mathrm{N}_{\mathrm{A}}$ is the Avogadro constant; 1 is the spacer thickness.

Table 2 summarizes the ionic conductivity and $\mathrm{D}_{\text {app }}$ value of poly(NAG) from temperature of $30^{\circ} \mathrm{C}$ to $65^{\circ} \mathrm{C}$. Compared to the pure liquid electrolyte holding a $\mathrm{D}_{\text {app }}$ value of $\mathrm{I}_{3}^{-}\left(1.15 \times 10^{-6} \mathrm{~cm}^{2} \cdot \mathrm{s}^{-1}\right)$, the $\mathrm{D}_{\text {app }}$ of poly(NAG) decreased to $0.655 \times 10^{-6} \mathrm{~cm}^{2} \cdot \mathrm{s}^{-1}$ at $30^{\circ} \mathrm{C}$. As can be seen from the Fig. $6 \mathrm{~b}, \mathrm{D}_{\text {app }}$ increases from $0.655 \times 10^{-6} \mathrm{~cm}^{2} \mathrm{~s}^{-1}$ to 1.459 $\times 10^{-6} \mathrm{~cm}^{2} \cdot \mathrm{s}^{-1}$ as the temperature rises. It might due to absolute viscosity of the solvent medium decreased.

In order to further evaluate the charge transfer capacity of the polymer electrolyte, the electrochemical impedance spectroscopy (EIS) was conducted as shown in Fig. 7a. The symmetrical cell using Pt coated FTO glass as the electrode, polymer poly(NAG) or pure liquid electrolyte were sandwiched between two electrodes. The charge transfer resistance $\left(\mathrm{R}_{\mathrm{cc}}\right)$ extracting from the first semicircle in EIS spectrum showed that the poly(NAG) electrolyte has a higher $\mathrm{R}_{\mathrm{ct}}$ than that of the pure liquid electrolyte. Higher $\mathrm{R}_{\mathrm{ct}}$ indicates lower charge transfer ability in the electrolyte/Pt interface.

Tafel polarization curves were used to confirm the electrocatalytic activity of the poly(NAG) electrolyte, the similar symmetry cells as the EIS test were used in the Tafel measurements. ${ }^{45}$ Parameters of the diffusion-limited currents density $\left(\mathrm{J}_{\lim }\right)$ and the exchange current density ( $\mathrm{J}_{0}$, when the applied bias is equal to zero) can be extracted by drawing the slope in the cathode or anode branch in the Tafel curves shown in Fig. 7b. It can be found that a larger exchange current density for pure liquid electrolyte $\left(\mathrm{J}_{1}^{0}\right)$ compared with that of poly(NAG) $\left(\mathrm{J}_{2}^{0}\right)$, indicating that the liquid electrolyte owns a better electrocatalytic activity toward the redox couples than that of the polymer electrolyte. ${ }^{33}$

\subsection{Photovoltaic performance of the QS-DSSCs}

The J-V curves of QS-DSSCs fabricated by the poly(NAG) electrolyte were tested under illumination with a simulated solar light of 100 $\mathrm{mW} \cdot \mathrm{cm}^{-2}$ (AM 1.5) as shown in Fig. 8. DSSCs employing poly(NAG) electrolyte achieved a conversion efficiency of $1.46 \%$, derived from a $\mathrm{J}_{\mathrm{sc}}$ of $3.732 \mathrm{~mA} / \mathrm{cm}^{2}, \mathrm{~V}_{\text {oc }}$ of $0.667 \mathrm{~V}$ and $\mathrm{FF}$ of $59 \%$. The relatively low performance of the QS-DSSCs might due to a low $\mathrm{J}_{\mathrm{sc}}$ value. Compared with the liquid electrolyte based DSSCs, the quasi-solid DSSCs using poly(NAG) showed a relative low efficiency. It might not be high enough for real applications. However, in terms of the improving the long-term stability of DSSCs, this commercial available polymer gel electrolyte demonstrated a feasible way for easy preparation and environmental benign approach. A few environmental friendly polymer electrolytes in DSSCs have also been summarized for comparison as listed in table 3. Among them, polymer electrolytes chosen from biopolymer such as kappa-carrageenan and cellulose derivatives, ${ }^{46}$ modified polysaccharide from seaweeds, ${ }^{47}$ polyurethane, ${ }^{48}$ Poly(ethylene oxide) blended with oligo- $\mathrm{PPG}^{49}$ were summarized. The polymer electrolyte showed comparable power conversion efficiency. It points out the future research direction in QS-DSSCs is to enhance the photocurrent density in order to compete with the liquid electrolyte DSSCs. This work shows a valuable attempt for using commercially available glue for simple and low cost fabrication of DSSCs. The solar cell efficiency can be further boosted by enhancing the electrolyte conductivity and interfaces between the electrolyte/Pt and electrolyte/photoanode.

Table 2 Ionic conductivity and $\mathrm{D}_{\text {app }}$ changes of poly(NAG) polymer electrolyte with temperature arise.

\begin{tabular}{|c|c|c|c|c|c|c|c|c|}
\hline Temperature $\left({ }^{\circ} \mathrm{C}\right)$ & 30 & 35 & 40 & 45 & 50 & 55 & 60 & 65 \\
\hline $\begin{array}{l}\text { Ionic conductivity } \\
\left(\mathrm{mS} \cdot \mathrm{cm}^{-1}\right)\end{array}$ & 0.260 & 0.317 & 0.356 & 0.389 & 4.391 & 5.018 & 5.713 & 6.886 \\
\hline Dapp $\left(\times 10^{-6}, \mathrm{~cm}^{2} \cdot \mathrm{s}^{-1}\right)$ & 0.655 & 0.735 & 0.839 & 0.965 & 1.103 & 1.183 & 1.229 & 1.459 \\
\hline
\end{tabular}



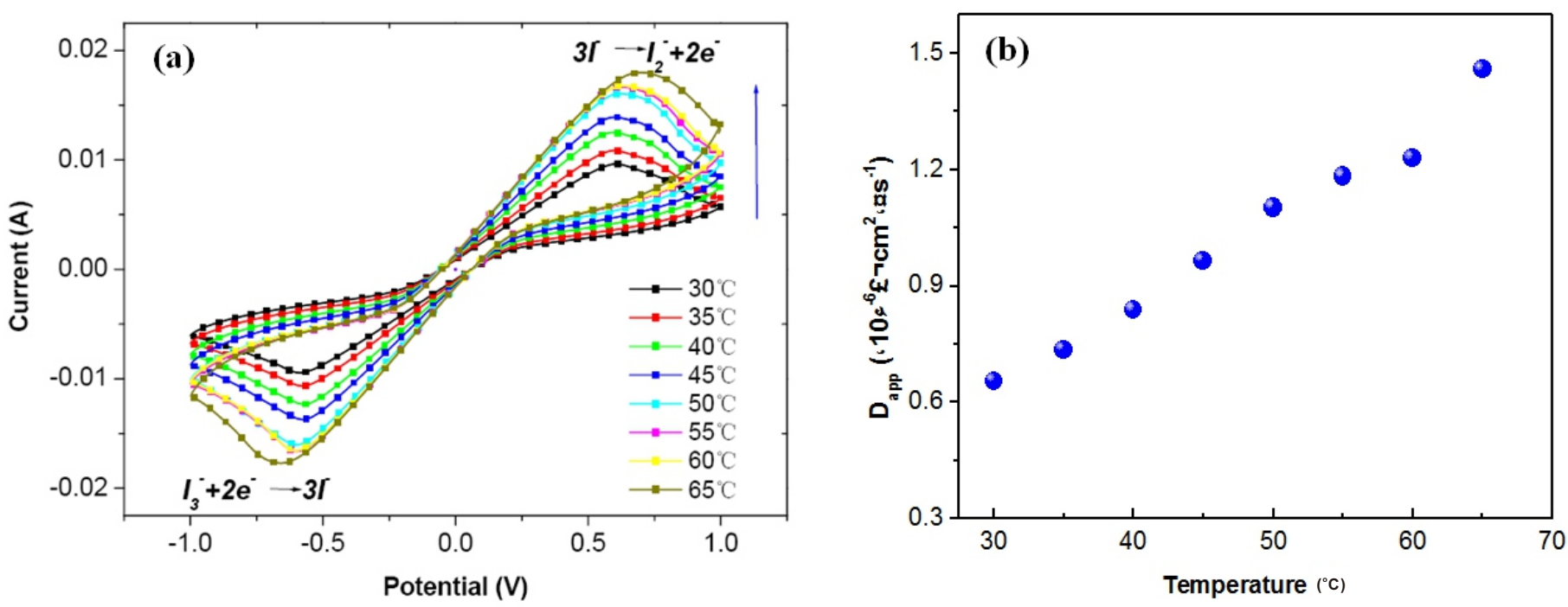

Fig. 6 (yclic voltammograms of the polymer electrolytes with ditterent temperature eftects (a) and trend of $\mathrm{D}_{\text {app }}$ with temperature raises (b).
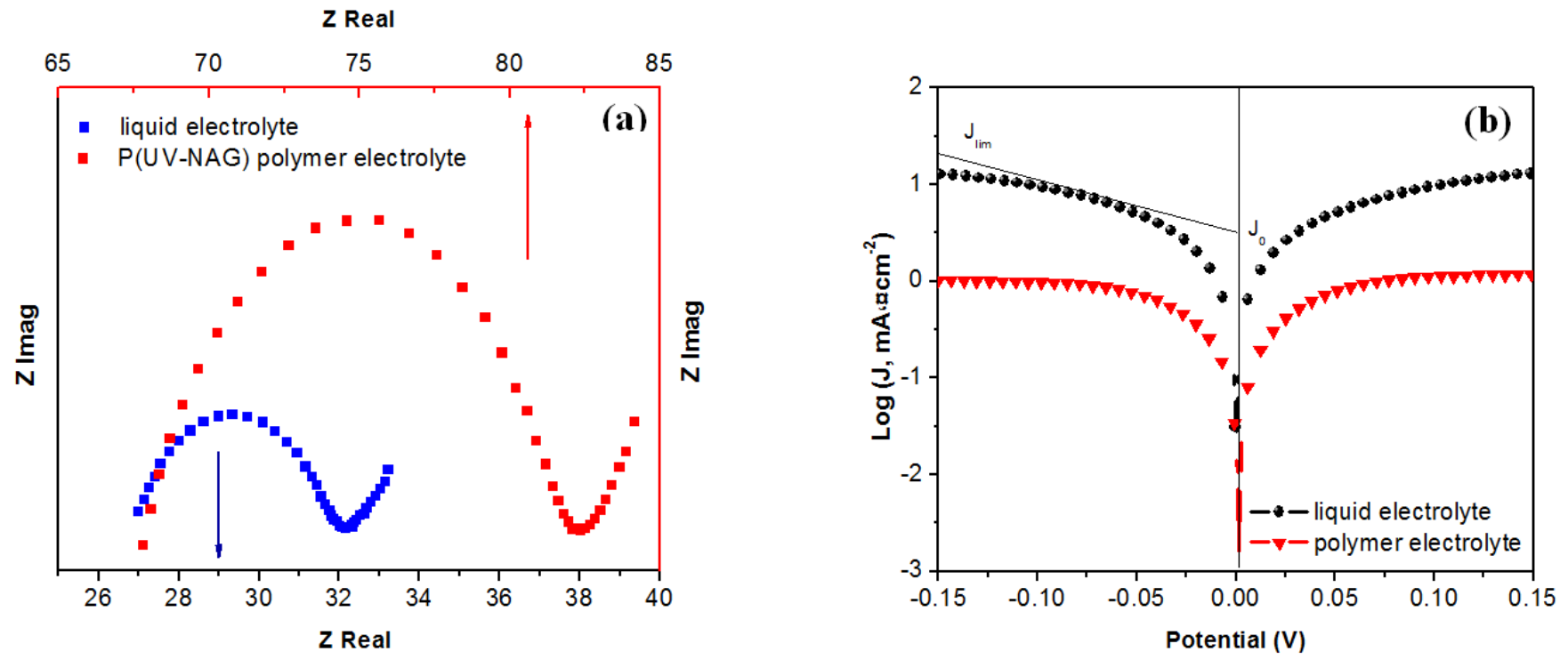

Fig. 7 Nyquist plots (a) and Tafel polarization curves (b) of the poly(NAG) and pure liquid electrolyte.

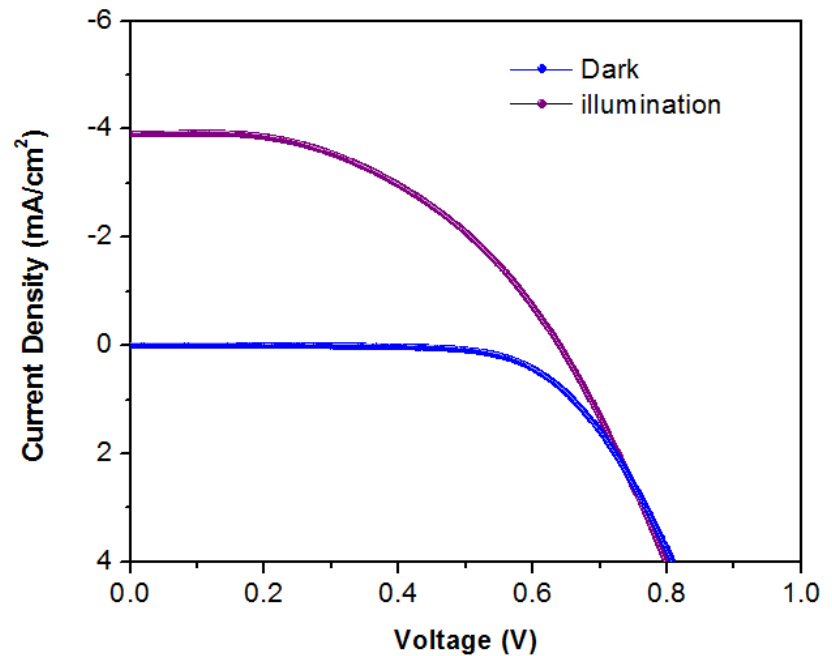

Fig. $8 \mathrm{~J}-\mathrm{V}$ curves of DSSC assembled with polymer poly(NAG) electrolyte under dark and light illumination.
Our future work would further improve the ionic conductivity by forming hybrid composites materials adapted from our previous work. ${ }^{50,51}$

\section{Conclusion}

In summary, a poly(NAG) polymer was successfully prepared by a rapid UV light induced photopolymerization method for dye sensitized solar cell application. The chemical composition of the NAG is revealed to be acrylate monomer. The polymer membrane is capable of retaining liquid electrolyte of $\mathrm{I}_{3}^{-} / \mathrm{I}^{-}$beyond $100 \%$ of its own weight and possessing outstanding wettability to liquid electrolyte. An ionic conductivity of $0.51 \mathrm{mS} \cdot \mathrm{cm}^{-1}$ was achieved at room-temperature for polymer poly(NAG) electrolyte and $1.46 \%$ of PCE was obtained under $100 \mathrm{~mW} \cdot \mathrm{cm}^{-2}$ for QS-DSSCs. It successfully demonstrates that this commercial glue NAG can be prepared as a novel polymer electrolyte for DSSCs. This novel polymer electrolyte appears as a promising candidate for the preparation of large-scale polymers useful to fabricate efficient DSSCs with low cost, simple operation and environment 
Table 3 A photovoltaic performance summary of DSSCs based on the polymer electrolyte reported in the literature and our work.

\begin{tabular}{lccccc}
\hline Polymer electrolyte & $\mathbf{V}_{\mathbf{o c}}(\mathbf{V})$ & $\mathbf{J}_{\mathbf{s c}}\left(\mathbf{m A} \cdot \mathbf{c m}^{-2}\right)$ & $\mathbf{F F}$ & $\boldsymbol{\eta}$ & Ref \\
\hline P(UV-NAG) & 0.667 & 3.732 & 0.59 & $1.46 \%$ & This work \\
Biopolymer electrolyte & & & 0.64 & $0.13 \%$ & 46 \\
CMKC/CMCE & 0.50 & 0.42 & & & \\
Modified polysaccharide & 0.51 & 7.60 & 0.53 & $2.06 \%$ & 47 \\
Polyurethane & 0.14 & 0.06 & 0.26 & $0.003 \%$ & 48 \\
Poly(ethylene oxide):oligo-PPG & 0.72 & 11.2 & 0.48 & $3.84 \%$ & 49 \\
\hline
\end{tabular}

friendly. The mechanic properties of the polymer electrolyte would also need to be considered for outdoor application or making flexible electronics devices. ${ }^{52-54}$

\section{Acknowledgements}

The authors sincerely thank the financial supports from the National Science Foundation of China (51502246), the Seed Foundation of Innovation and Creation for Graduate Students at Northwestern Polytechnical University (NWPU) (ZZ2018187) and Undergraduate Student Innovation Training Program of NWPU (201710699284).

\section{References}

1. T. Xu, L. Chen, Z. Guo and T. Ma, Phys. Chem. Chem. Phys., 2016, 18, 27026-27050.

2. T. Xu and Q. Qiao, Energy Environ. Sci., 2011, 4, 2700-2720.

3. H. Chen, T. Liu, B. Wang, Z. Liu, Y. Li, Q. Zhao, N. Wang, H. He, H. Liu and Z. Guo, Adv. Compos. Hybrid Mater., 2018, 1, 356-363.

4. T. Liu, K. Yu, L. Gao, H. Chen, N. Wang, L. Hao, T. Li, H. He and Z. Guo, J. Mater. Chem. A, 2017, 5, 17848-17855.

5. Q. Hou, J. Ren, H. Chen, P. Yang, Q. Shao, M. Zhao, X. Zhao, H. He, N. Wang, Q. Luo and Z. Guo, Chem. Electro. Chem., 2018, 5, 726-731.

6. Q. Luo, H. Ma, Q. Hou, Y. Li, J. Ren, X. Dai, Z. Yao, Y. Zhou, L. Xiang, H. Du, H. He, N. Wang, K. Jiang, H. Lin, H. Zhang and Z. Guo, Adv. Funct. Mater, 2018, 28, 1706777.

7. K. Kakiage, Y. Aoyama, T. Yano, K. Oya, J. I. Fujisawa and M. Hanaya, Chem.Commun., 2015, 51, 15894-15897.

8. J. Wu, Z. Lan, J. Lin, M. Huang, Y. Huang, L. Fan and G. Luo, Chem. Rev,, 2015, 115, 2136-2173.

9. U. Bach, D. Lupo, P. Comte, J. E. Moser, F. Weissörtel, J. Salbeck, H. Spreitzer and M. Grätzel, Nature, 1998, 395, 583.

10. I. Chung, B. Lee, J. He, R. P. H. Chang and M. G. Kanatzidis, Nature, 2012, $485,486$.

11. S. Abdulkarim, H. Elbohy, N. Adhikari, M. N. Hasan, W. Yue and Q. Qiao, J. Phys. Chem. C, 2017, 121, 21225-21230.

12. L. Wang, H. Zhang, C. Wang and T. Ma, ACS Sust. Chem. Eng., 2013, 1, 205-208.

13. J. V. Vaghasiya, K. K. Sonigara, T. Beuvier, A. Gibaud and S. S. Soni, Nanoscale, 2017, 9, 15949-15957.

14. G. G. Sonai, A. Tiihonen, K. Miettunen, P. D. Lund and A. F. Nogueira, J. Phys. Chem. C, 2017, 121, 17577-17585.

15. S. Angaiah, V. Murugadoss, S. Arunachalam, P. Panneerselvam and S. Krishnan, Eng. Sci., 2018, 4, 44-51.

16. S. H. Park, J. Lim, I. Y. Song, J. R. Lee and T. Park, Adv. Energy Mater, 2014, 4, 136-140

17. M. A. K. L. Dissanayake, W. N. S. Rupasinghe, V. A. Seneviratne, C. A. Thotawatthage and G. K. R. Senadeera, Electrochim. Acta, 2014, 145, 319326.
18. S. Venkatesan, I. P. Liu, J. C. Lin, M. H. Tsai, H. Teng and Y. L. Lee, $J$ Mater. Chem. A, 2018, 6, 10085-10094.

19. A. R. S. Priya, A. Subramania, Y. S. Jung and K. J. Kim, Langmuir, 2008, 24, 9816-9819.

20. J. Y. Lee, B. Bhattacharya, D. W. Kim and J. K. Park, J. Phys. Chem. C, 2008, 112, 12576-12582.

21. F. Bella and R. Bongiovanni, J. Photoch. Photobio. C, 2013, 16, 1-21.

22. T. Kato, A. Okazaki and S. Hayase, Chem. Commun., 2005, 363-365.

23. W. He, L. Chen, T. Xu, D. Wei and Y. Wang, Ceram. Int., 2015, 41, 1044810455

24. D. M. Han, K. W. Ko, C. H. Han and Y. S. Kim, J. Mater. Chem. A, 2013, 1, 8529-8533.

25. M. K. Parvez, I. In, J. M. Park, S. H. Lee and S. R. Kim, Sol. Energy Mat Sol. C., 2011, 95, 318-322.

26. M. Imperiyka, A. Ahmad, S. A. Hanifah and F. Bella, Physica B., 2014, 450, 151-154.

27. F. Bella, D. Pugliese, J. R. Nair, A. Sacco, S. Bianco, C. Gerbaldi, C. Barolo and R. Bongiovanni, Phys. Chem.Chem. Phys., 2013, 15, 3706-3711.

28. F. Bella, N. Vlachopoulos, K. Nonomura, S. M. Zakeeruddin, M. Gratzel, C. Gerbaldi and A. Hagfeldt, Chem.Commun., 2015, 51, 16308-16311.

29. S. Qu, Y. Yu, K. Lin, P. Liu, C. Zheng, L. Wang, T. Xu, Z. Wang and H. Wu, J. Mater. Sci-Mater. El., 2018, 29, 1232-1237.

30. X. Qin, Y. Huang, K. Wang, T. Xu, Y. Wang, P. Liu, Y. Kang and Y. Zhang, Electrochim. Acta., 2019, 297, 805-813.

31. B. Kirubasankar, V. Murugadoss, J. Lin, T. Ding, M. Dong, H. Liu, J. Zhang, T. Li, N. Wang, Z. Guo and S. Angaiah, Nanoscale, 2018, 10, 20414-20425.

32. W. Zhao, X. Li, R. Yin, L. Qian, X. Huang, H. Liu, J. Zhang, J. Wang and T. Ding, Z. Guo, Nanoscale, 2019.

33. T. Xu, J. Li, R. Gong, Z. Xi, T. Huang and L. Chen, T. Ma, Ionics, 2018, 24, 2621-2629.

34. S. Ito, T. N. Murakami, P. Comte, P. Liska, C. Grätzel, M. K. Nazeeruddin and M. Grätzel, Thin Solid Films, 2008, 516, 4613-4619.

35. G. Liang, Z. Zhong, S. Qu, S. Wang, K. Liu, J. Wang and J. Xu, Journal of Materials Science 2013, 48, 6377-6385.

36. J. R. Nair, L. Porcarelli, F. Bella and C. Gerbaldi, ACS Appl. Mater. Int., 2015, 7, 12961-12971.

37. T. Xu, S. Venkatesan, D. Galipeau and Q. Qiao, Sol. Energy Mat. Sol. C., 2013, 108, 246-251.

38. S. Y. Lee, B. Yoo, M. K. Lim, T. K. Lee, A. R. S. Priya and K. J. Kim, Langmuir, 2010, 26, 6638-6642.

39. A. A. Mohamad, J. Power Sources, 2016, 329, 57-71.

40. N. M. Franson and N. A. Peppas, J. Appl. Polym.Sci.,1983, 28, 1299-1310.

41. J. Duan, Q. Tang, R. Li, B. He, L. Yu and P. Yang, J. Power Sources., 2015, 284, 369-376.

42. S. Yuan, Q. Tang, B. He and P. Yang, J. Power Sources, 2014, 254, 98-105.

43. S. Yuan, Q. Tang, B. Hu, C. Ma, J. Duan and B. He, J. Mater. Chem. A, 2014, 2, 2814-2821.

44. K. Fricke, F. Harnisch and U. Schroder, Energy Environ. Sci., 2008, 1, $144-$ 147.

45. S. J. Kim, J. Kwon, J. K. Nam, W. Kim and J. H. Park, Electrochim. Acta, 
2017, 227, 95-100.

46. S. Rudhziah, A. Ahmad, I. Ahmad and N. S. Mohamed, Electrochim. Acta, 2015, 175, 162-168.

47. F. Bella, N. N. Mobarak, F. N. Jumaah and A. Ahmad, Electrochim. Acta, 2015, 151, 306-311.

48. M. S. Su'ait, A. Ahmad, K. H. Badri, N. S. Mohamed, M. Y. A. Rahman, C. L. A. Ricardo and P. Scardi, Int. J. Hydrogen Energ., 2014, 39, 3005-3017.

49. M. S. Kang, J. H. Kim, Y. J. Kim, J. Won, N. G. Park and Y. S. Kang, Chem.Commun., 2005, 889-891.

50. T. Xu, J. Hu, Y. Yang, W. Que, X. Yin, H. Wu and L. Chen, J. Alloys
Compd., 2018, 734, 196-203.

51. T. Xu, J. Hu, Y. Yang, W. Que, X. Yin, H. Wu and L. Chen, J. Mater. SciMater. El., 2018, 29, 4888-4894.

52. T. Huang and Y. Wang, G. Wang, Polym-Plast Technol., 2018, 57, 740-756.

53. T. Huang, Y. Gong and S. Zhao, J. Eng. Mech., 2018, 144, 06017019.

54. T. Huang and Y. Gong, Compos. Struct., 2018, 185, 401-410.

Publisher's Note Engineered Science Publisher remains neutral with regard to jurisdictional claims in published maps and institutional affiliations. 